San Jose State University

SJSU ScholarWorks

Faculty Research, Scholarly, and Creative Activity

6-14-2019

\title{
Platforms as entrepreneurial incubators? How online labor markets shape work identity
}

\author{
Francesca Bellesia \\ University of Bologna \\ Elisa Mattarelli \\ San Jose State University, elisa.mattarelli@sjsu.edu \\ Fabiola Bertolotti \\ University of Modena and Reggio Emilia \\ Maurizio Sobrero \\ University of Bologna
}

Follow this and additional works at: https://scholarworks.sjsu.edu/faculty_rsca

Part of the Entrepreneurial and Small Business Operations Commons, and the Technology and Innovation Commons

\section{Recommended Citation}

Francesca Bellesia, Elisa Mattarelli, Fabiola Bertolotti, and Maurizio Sobrero. "Platforms as entrepreneurial incubators? How online labor markets shape work identity" Journal of Managerial Psychology (2019):

246-268. https://doi.org/10.1108/JMP-06-2018-0269

This Article is brought to you for free and open access by SJSU ScholarWorks. It has been accepted for inclusion in Faculty Research, Scholarly, and Creative Activity by an authorized administrator of SJSU ScholarWorks. For more information, please contact scholarworks@sjsu.edu. 
See discussions, stats, and author profiles for this publication at: https://www.researchgate.net/publication/332606467

\section{Platforms as Entrepreneurial Incubators? How Online Labor Markets shape Work Identity}

Article in Journal of Managerial Psychology · March 2019

DOI: 10.1108/JMP-06-2018-0269

CITATIONS

2

4 authors:

Francesca Bellesia

Università degli Studi di Modena e Reggio Emilia

12 PUBLICATIONS 18 CITATIONS

SEE PROFILE

Fabiola Bertolotti

Università degli Studi di Modena e Reggio Emilia

52 PUBLICATIONS 626 CITATIONS

SEE PROFILE
READS

593

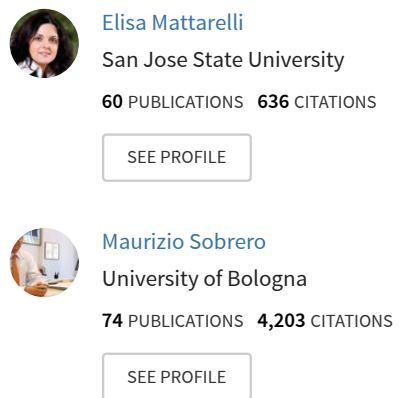

Some of the authors of this publication are also working on these related projects:

ExpMTM - Investigating multi-level effects of Multiple Team Membership through experiments View project

Understanding Hybrid Interorganizational Partnerships: Identity Formation, Decision Pathologies, Business Model Innovation and Governance Change View project 
Forthcoming Journal of Managerial Psychology

PLEASE DO NOT DISTRIBUTE WITHOUT AUTHORS'PERMISSION

\title{
Platforms as Entrepreneurial Incubators?
}

\section{How Online Labor Markets Shape Work Identity}

\author{
Francesca Bellesia \\ Dipartimento di Scienze Aziendali \\ University of Bologna \\ francesca.bellesia4@unibo.it
}

Elisa Mattarelli

Dipartimento di Scienze e Metodi dell'Ingegneria

University of Modena and Reggio Emilia

\section{Fabiola Bertolotti}

Dipartimento di Scienze e Metodi dell'Ingegneria

University of Modena and Reggio Emilia

\section{Maurizio Sobrero}

Dipartimento di Scienze Aziendali

University of Bologna 


\title{
Platforms as Entrepreneurial Incubators? How Online Labor Markets Shape Work Identity
}

\begin{abstract}
Purpose. This study explores how the process of work identity construction unfolds for gig workers experiencing unstable working relationships in online labor markets. In particular, it investigates how digital platforms, intended both as providers of technological features and online environments, affect this process.

Design. We conducted an exploratory field study and collected data from 46 interviews with freelancers working on one of the most popular online labor markets and from online documents such as public profiles, job applications, and archival data.

Findings. Our findings reveal that the online environment constrains the action of workers who are pushed to take advantage of the platform's technological features to succeed. This interplay leads workers to add new characteristics to their work self and they end up developing an entrepreneurial orientation.

Practical implications. Our study offers insights to platform providers interested in improving workers' experiences in online labor markets, highlighting mechanisms for uncertainty reduction, and diversifying a platform's services according to gig workers' identities and orientations.

Value. Our study expands our knowledge on work identity construction processes of gig workers, detailing the relationship between work identity and IT, and documents previously unexplored antecedents of entrepreneurial orientation in non-standard working contexts.
\end{abstract}




\section{Introduction}

Individuals strive to define their identity, i.e. a clear sense of "who I am", in the different contexts of their lives and, in particular, in the workplace (Ashforth and Schinoff, 2016). Extant literature (e.g. Dutton et al., 2010; Gecas, 1982; Ibarra, 1999; Petriglieri et al., 2018; Petriglieri and Petriglieri, 2010; Pratt, 2000; Pratt et al., 2006) has paid significant attention to the processes through which individuals define and build their work identities - i.e. the values, beliefs, and attributes they use to define themselves in the workplace (Ibarra, 1999) - as work identities are closely related to how individuals behave and perform as workers (Alvesson et al., 2008; Koppman et al., 2016).

Until recently, researchers have studied the 'world of work' (Ashford et al., 2018) mainly in terms of stable employment relationships and career transitions within or between organizations, in accordance with the times of job security and economic stability that have characterized many Western Countries for almost half a century. Consistently, existing identity literature has often explored organizational contexts (e.g., companies, NGOs, public organizations), showing that organizations offer their employees values, tools and resources to support the development of a coherent sense of self (Ashforth and Schinoff, 2016), and to foster organizational-coherent behaviors (Alvesson et al., 2008; Ashforth and Schinoff, 2016; Pratt, 2000). Nonetheless, over the past few decades, given extensive economic and technological changes, career trajectories have become less linear as individuals not only change jobs more frequently, but also engage more in independent or temporary work (Ashford et al. 2007;

Connelly and Gallagher 2004; Hollister 2011; Stone et al. 2015). Consequently, scholars have started to question the validity and applicability of existing management theories to explain the behavior of workers in the new world of work (Ashford et al., 2018; Cappelli and Keller, 2013; 
Forthcoming Journal of Managerial Psychology

PLEASE DO NOT DISTRIBUTE WITHOUT AUTHORS' PERMISSION

Furnham, 2006; Sparrow, 2000; Spreitzer et al., 2017), where people often experience

uncertainty and reside 'in between' organizations, occupations, and other communities (Carton and Ungureanu, 2018; Ibarra and Obodaru, 2016).

Since the uncertain conditions that workers experience in new labor markets are strongly intertwined with how they define and perceive themselves as professionals (Ibarra and Obodaru, 2016), in this paper we intend to address scholarly concerns on the applicability of existing identity theories, and understand how individuals from a growing, although underexplored, category of workers - i.e. gig workers - construct their work identity. The working condition of gig workers, who deliver short-term jobs on demand - i.e. "gigs" -, makes them more likely to experience feelings of job insecurity (Lam et al., 2015; Spreitzer et al., 2017), as they are neither employed by a single organization, nor experience a classic organizational setting, where exposure to social relations with colleagues and role expectations help to forge a coherent work identity.

The literature on temporary and contract workers suggests that, even in uncertain conditions, individuals still need a reference environment to nurture identities, like occupations (Barley and Kunda, 2006), personal holding environments (Petriglieri et al., 2018), online communities (Langner and Seidel, 2015), or client organizations (George and Chattopadhyay, 2005). Gig workers are increasingly making use of digital platforms like Freelancer.com, Guru, or Upwork which regulate the relation between workers and employers in so called 'online labor markets' (Boudreau and Lakhani, 2013). To give an example, a single digital platform such as Freelancers.com counted more than 32 million registered users and more than 15 million posted 'gigs' in 2018. We argue that the online environment and the technological features offered by platforms may act as references in the process of workers' work identity construction. Workers 
need to learn how to navigate the platform's rules and procedures to get jobs, execute activities, and get paid for their work (Kuhn and Maleki, 2017). In addition, platforms increase the level of global distribution and competition that workers face (Boudreau et al., 2015; Spreitzer et al., 2017), further escalating the conditions of uncertainty that any freelancer experiences.

We thus propose that studying identities is relevant to learn gig workers' behavioral trajectories in online labor markets, with implications both for theoretical development as well as for practical implications. Concerning the latter, acknowledging the impact of technology on these trajectories may help in deriving implications to design appropriate platform's support mechanisms. We then formulate our research question as follows: How do technological platforms influence gig workers' work identity construction and with what consequences?

To address our research question, we draw evidence from interviews and documents collected from workers using a major online labor market platform. We build a grounded model showing how work identity is empowered in response to a constraining online environment, by strategically using platform technological features. Specifically, we show how such processes lead individuals to build a new work identity characterized by an entrepreneurial orientation. Our study contributes to the current scholarly conversation on the relation between technology and identity construction and the antecedents of entrepreneurial orientation in online labor markets.

\section{Theoretical Background}

\section{Work-Identity and Gig Workers}

In this study, we are interested in that part of an individual identity concerning the enactment of a work-related role, that is, work identity (Ibarra, 1999). The identity literature has both developed rich theory and provided examples of individuals elaborating on their work identity during 
Forthcoming Journal of Managerial Psychology PLEASE DO NOT DISTRIBUTE WITHOUT AUTHORS'PERMISSION

significant role transitions - i.e. newcomers in organizations or people taking up new positions after promotions (Ashforth and Schinoff, 2016; Ibarra 1999) - or in particularly demanding circumstances - e.g., when people perceive that what they do does not match with who they are (Mattarelli and Tagliaventi, 2015; Pratt et al., 2006). In these cases, people experience uncertain conditions and existing identities are under threat, either because they need to adapt to new roles, or because they need to be socialized in a new organizational context (Pratt et al., 2006). For instance, Ibarra (1999) shows that individuals adapt to new organizational roles by trying temporary solutions - i.e. provisional selves - to deal with the lack of alignment between their identity and expectations about a new organizational role. Other studies show that when individuals enter new organizations, organizations manage their identity through circles of sensebreaking - i.e. creating a sense of liminality and motivating individuals to search for new meanings - and sense-giving - i.e. attempts to influence the new meanings according to organizational preferences (Alvesson et al., 2008; Ashforth and Schinoff, 2016; Pratt, 2000). Even in virtual contexts, research has shown that organizations take advantage of technological tools to support identity processes for virtual workers and, therefore, increase their level of commitment, and preserve control over their work (Thatcher and Zhu, 2006; Wiesenfeld et al., 1999, 2001). Organizations and professional communities have been then described as fundamental in the process of individual identity construction (Alvesson et al., 2008; Ashforth and Schinoff, 2016; Ibarra, 1999; Mattarelli and Tagliaventi, 2015; Pratt, 2000; Pratt et al., 2006), as they provide values, meanings and examples that individuals can use to build their work identities.

Differently from these studies, gig workers operate in a distributed context and are only temporarily hired by organizations or individual clients, therefore lacking the social environment 
Forthcoming Journal of Managerial Psychology PLEASE DO NOT DISTRIBUTE WITHOUT AUTHORS' PERMISSION

they can use to derive ideal images of a possible or desirable self at work (Ibarra, 1999). In particular, in distributed contexts, individuals face more difficulties in deriving cues to foster their work identities. However, how non-traditional workers, such as contract workers, temporary workers, and gig workers answer the question "Who am I?" has received limited attention (Barley et al., 2017; Barley and Kunda, 2006; George and Chattopadhyay, 2005; Petriglieri et al., 2018). In their ethnographic study of technical contractors in a contingent labor market, Barley and Kunda (2006) define contractors as "itinerant professionals" (Barley and Kunda, 2006, p. 50) who mainly draw from personal skills to categorize themselves, making contracting a new form of professionalism. Thus, compared to workers in institutionalized occupations, the authors highlight the predominant role of agency in contract workers' experience. More recently, Petriglieri and colleagues (2018) have emphasized the importance of agency through their study of independent workers in precarious working conditions. In particular, these authors argue that workers lacking a stable physical and social environment e.g., organizations - tend to develop physical, social, and psychological spaces, i.e. personal "holding environments", to sustain meaning and routines, and to deal with feelings of anxiety and fear (Petriglieri et al., 2018). George and Chattopadhyay (2005) investigated the process of identification of contract workers employed by their work organization, but actually working inside their client organization. Results indicate that workers identify with their employer and their client, thereby developing a dual identification.

Although this research has generated theory and descriptions of what happens when individuals lack stable affilitations, it does not incorporate the complexities derived from the distribution of work and mediation of technology that gig workers experience. Gig workers in online labor markets work in technology-intensive contexts - i.e. the platform they subscribe to - 
Forthcoming Journal of Managerial Psychology

PLEASE DO NOT DISTRIBUTE WITHOUT AUTHORS'PERMISSION

which, we argue, may offer support to identity construction. For instance, platforms may provide access to online communities to foster workers' socialization, or they may provide narratives about best workers to influence individual images, ultimately influencing identity construction processes. Gig workers may therefore operate in a 'hybrid' workspace, where, on the one hand, they are alone and fully take risks associated to their job, and, on the other, they are influenced by the rules imposed by the platform.

Although previous studies on contract or independent work have not specifically addressed and explored technology-intensive contexts, especially the relation between technology and identity, research in the domain of information technology and information systems has more deeply addressed this relation (e.g. Carter and Grover, 2015; Lamb and Davidson, 2005; Stein et al., 2013). We therefore take a closer look at it to further inform our research question.

\section{Identity and Platforms}

In the last decade, there has been increasing attention towards the relation between identity and information technology in the information systems literature (see Carter and Grover, 2015, for a review). Among studies expanding theory at the individual level of analysis, some have focused on how features of a newly-introduced technology induced changes in work practices and affected professional identity construction or recovery (Van Akkeren and Rowlands, 2007; Boudreau et al., 2014; Lamb and Davidson, 2005; Stein et al., 2013). Van Akkeren and Rowlands (2007) showed that the introduction of a Healthcare Information System in a team of radiologists provoked anxiety and struggles to assimilate the new features of the technology into work practices, leading to a redefinition of role identities. Similarly, Lamb and Davidson (2005) found evidence that technology impacted the practices for data collection and results 
Forthcoming Journal of Managerial Psychology PLEASE DO NOT DISTRIBUTE WITHOUT AUTHORS'PERMISSION

dissemination of marine biologists, who took advantage of new technological features to improve their job and strengthen their work identity by creating new areas of expertise. In this case, technology features led to the empowerment of already existing professional identities. Other studies have shown that technology can foster the enactment of different selves instead of fueling existing identities. For instance, in the study by Stein and colleagues (2013) the material features of technology affect employees' identity enactment so that these features become part of a professional narrative of the self. The study also showed that technology may help workers to try out different preferred selves before allowing the enactment of a single preferred identity. Similarly, Boudreau and colleagues (2014) showed how technology was used to experiment with multiple provisional identities during the introduction of a new information system in a library. Siles (2012) showed how technological artifacts, i.e. web sites and blogs, sustain the emergence of a new identity anchored to the technological artifact itself, and, recently, information technology (IT) has been theorized as an integral part of the individual's sense of self (i.e., IT identity, Carter and Grover, 2015). Carter and Grover (2015) introduce IT identity by arguing that through the experience of technological features, individuals are likely to develop a closer than previously theorized relation with IT, that ultimately influences their technology use behavior. Their theorization suggests that technology is the 'endurance support' to identity construction, maintenance, and change.

These different findings interpret technology as an enabler for new work identities or look at specific features that lead to adaptation of existing identities. We argue that none of these perspectives alone can help us to fully understand the processes of identity construction for gig workers using online platforms. In the gig economy, online platforms may provide access to new work opportunities and new tools to freelancers to interact with their clients, but they may also 
be considered vehicles for completely new working arrangements, as gig workers need to learn the rules of the game they are playing (e.g. rating systems, payment methods). As new working environments, platforms may provide the ground for people to experiment with multiple (Boudreau et al., 2014), existing (Lamb and Davidson, 2005), or unforeseen work identities (Siles, 2012), supplanting and/or complementing the role played by organizations and professions.

Few authors speculating on the impact of an online environment suggest that an online environment creates identity struggles, since it is assumed that individuals need to show the same identity both online and offline (Lamb and Davidson, 2005). There has also been evidence that interactions in an online environment lead to the construction of a new type of identity associated with how individuals see and present themselves online - i.e. virtual identity (Moon et al., 2006). Thus, we argue that interpreting platforms not only as tools composed of a set of features, but also as new working environments, requires us to think in new ways about the relationship between IT and identity construction processes. Although Carter and Grover's (2015) IT identity theorization goes in this direction, it still considers technology as a tool composed by features, and not as an environment that might constrain individual action. Consistently, the authors talk about a positive influence of technology on identity that manifests in enduring feelings of emotional attachment to the technology, i.e. emotional energy; reliance upon the technology, i.e. dependence; and feelings of connectedness with the technology, i.e. relatedness (Carter and Grover, 2015, p. 945). Moreover, their theorization does not explain what happens when this ITself interacts with the work-self. New insights are therefore needed to understand the relation between platforms and gig workers, as platforms are at the same time carriers of specific technological features and enablers of online work environments. 


\section{Methodology}

\section{Research Setting}

The lack of knowledge and studies encapsulating platforms as online environments and as a set of features, and the questions about the applicability of existing identity theories in online labor markets, call for a research design that allows to develop theoretical depth and detailed understanding of new, unexplored phenomena. We then decided to conduct an exploratory field study on one of the most popular online labor market (OLM) platforms, following the grounded theory approach described by Strauss and Corbin (1998), which represents a suitable methodology for developing new theories grounded in the context and in the words of informants.

The OLM platform we studied matches buyers and sellers of services. Here, clients (i.e. individuals or entire organizations) delegate single projects or small jobs to geographically distributed individuals connected via the Internet. In particular, at the time of the study, the platform had over 13 million registered users in more than 100 countries. Clients can hire contractors to deliver complex, high-skilled jobs, from graphic design to virtual assistance, from software and mobile development to translations. Platforms offer a digital environment where organizations can post their requests and contractors can find jobs fitting their specific skills. Each worker has his/her online profile where he/she can provide both personal and work-related information. The profile also tracks freelancers' working history (e.g., total number of worked hours) and performance details (e.g., success rate). Once a client has found his/her freelancer, they sign a contract and start a working relationship. Interactions take place at a distance and are mediated by technological tools, either provided by the platform or decided by the parties. At the 
Forthcoming Journal of Managerial Psychology

PLEASE DO NOT DISTRIBUTE WITHOUT AUTHORS'PERMISSION

end of the contract, both parties access the feedback system and rate their working experience, that is, clients provide a blind feedback to workers and vice-versa. Jobs can be rewarded on an hourly basis or through fixed contracts.

\section{Data Sources}

We rely on semi-structured interviews, archival documents downloaded from the platform, and the personal online profiles of our informants to support our theory building process.

Semi-structured interviews. We conducted, recorded, and transcribed 46 semi-structured interviews of about 75 minutes each, with freelancers subscribed to the platform. The first author subscribed to the platform and posted different requests for interviews, offering a fixed monetary reward, usually between 8 and 12 US dollars. A similar approach was used by other studies, which administered online surveys through OLM platforms for investigating digital labor dynamics (e.g. Deng et al., 2016; see Behrend et al., 2011; and Steelman et al., 2014 for methodological issues in using M Turk for surveys). Consistently with Kapelner and Chandler (2010), who showed that monetary compensation is not a primary motivation to participate in online studies, our informants decided to participate because of their interest in the results, their willingness to be part of a research project, or the desire to share and voice their experience. This is why many informants suggested a lower reward or refused to be paid.

We chose respondents following theoretical sampling techniques. For instance, European IT developers guessed about different strategies that Asian developers used to manage competition and build job applications, as they talked about Asian IT developers as their main competitors. Therefore, we decided to contact Asian IT developers to further confirm or refine our categories associated to the strategic use of technological features. Similarly, we decided to 
extend our sample to designers to include a different job category and verify the solidity of our findings. Table 1 provides more information about our sample.

---- Insert Table 1 around here ----

During interviews, we first asked informants general questions about their working history and the motivations to join the platform. Then, we moved to identity-related issues and feelings about the job, drawing inspiration for questions from the work of Petriglieri and colleagues (2018). Examples of questions include: How do you organize your working day? Could you describe me the kind of work that you do on the platform? Could you please describe a positive experience that you had on the platform, and why you considered it as positive? Finally, we asked questions about their interpretation and use of the platform. After the first ten interviews, we realized that informants often mentioned how their experience on the platform stirred a desire to open their own business and be engaged in entrepreneurial activities. Given the centrality of this theme for identity construction, we then modified our protocol and explored such issues in all subsequent interviews.

Our interviews continued until we realized that new data were not adding new pieces of information and were not helping us further refine or develop our model - i.e. theoretical saturation (Glaser and Strauss, 1967). For instance, we ended our data collection once we realized that new data were not helping us refining our categories related to the construction of work identity (e.g., the aggregate dimension Development of an Entrepreneurial Orientation). Online Profiles, Job Applications, and Archival Data. We also analyzed our informants' public online profiles to grasp additional information about their working experiences and their identity, how they present themselves online, and their status on the platform. We started this examination immediately before the interviews in order to address specific questions on the information 
Forthcoming Journal of Managerial Psychology

PLEASE DO NOT DISTRIBUTE WITHOUT AUTHORS' PERMISSION

provided in their profile. Through this approach we could understand how respondents strategically used their profiles in the online environment. To grasp additional information on these issues, we also asked informants to share examples of past job applications, collecting 37 proposals. Finally, we reviewed some articles and reports posted on the platform's blog to further develop an enriched understanding of the context. These documents mainly reported information about the platform itself and offered tips to freelancers.

Analysis

We built an integrated database with interviews, profiles, job applications, and documents. Data analysis followed the framework proposed by Strauss and Corbin (1998) for grounded theory development and the three-step coding process inspired by the so-called "Gioia methodology" (Gioia et al., 2013). Under these frameworks, data analysis went hand in hand with the data collection stage (Strauss and Corbin, 1998). We adopted an iterative approach of constant comparison among the literature, emerging interpretation of data, and new data from the field. We first open-coded to search for recurrent first order concepts. We then grouped them to create categories, and finally aggregated theoretical dimensions. As the last step of this procedure, we identified relationships between categories. For example, we ran a first step searching for regularities and patterns among data and found that freelancers mainly described job applications as useful tools to fit job calls, and profiles as useful to provide clients tangible proof of their abilities. We then recognized these behaviors as strategies to 'sell' individual skills and decided to group them together. Then, while going back and forth between theory and data, we interpreted them as technological features offered by the platform. Finally, we searched for relations between categories and further examined our data to identify which characteristics associated to the online environment and strategic use of technological features triggered work 
Forthcoming Journal of Managerial Psychology

PLEASE DO NOT DISTRIBUTE WITHOUT AUTHORS'PERMISSION

identity construction. We used the software NVivo to support the entire process. The final output of this procedure was the data structure and the grounded model provided in Figure 1 and Figure 2.

---- Insert Figure 1 about here ----
---- Insert Figure 2 about here ----

\section{Findings}

Our grounded model (see Figure 2) shows how constraints and features of the platform lead individuals to add new meanings to their work identity and, ultimately, how this new work identity was associated to an entrepreneurial orientation. The model starts with the motives pushing individuals towards online labor markets.

\section{Motives}

Our informants shared their motives to join online labor markets. In particular, they explained how online work helped them to fulfill needs related to monetary compensation, fun, work flexibility, learning, and stagnant local labor markets. For instance, many informants described online jobs as second sources of income and as a way to make use of their spare time, as in the following excerpt:

"You can just tell that I am here for relaxation, because when I work here is a different thing, different people, and also I can make some money. My personal opinion is that if I am capable to do a lot of work, then I should do it. I don't waste time, if I have the opportunity I should work as much as possible". [Theodor, IT developer]

Some freelancers expressed the need to work from home for family or location reasons and referred to flexibility as one of the biggest advantages. Others desired to escape from the "boring" activities of their offline jobs. Finding ways to keep in touch with the latest technology developments and "remaining in the learning cycle" was also mentioned as one of the motives. 
Forthcoming Journal of Managerial Psychology

PLEASE DO NOT DISTRIBUTE WITHOUT AUTHORS'PERMISSION

We also talked with students joining the platform to test their knowledge and then sell their competencies in the traditional job market as professionals with an extensive portfolio, despite being recent graduates without 'traditional' working experience. Finally, some informants lamented difficulties in finding jobs suitable to their skills in their countries and, therefore, joined global online labor markets for lack of local alternatives.

To fulfill these needs, individuals needed to make immediate sense of the platform's mechanisms and identify ways to succeed. Through experience, they acquired knowledge about the online environment and learned to use a given platform's features to circumvent perceived constraints. We proceed in the following pages by describing how individuals matched specific online constraints to specific uses of features of the platform. We then discuss the consequences of such matching processes for identity construction.

Global Competition, Acquiring Knowledge of the Market, and Becoming a Unique Online Worker

Global competition. Competition on the platform was often labelled as "hard" and perceived as a constraint to individual success. Whoever owns an Internet connection can sell individual skills on the platform; thus, workers face a global competition and deal with different working conditions and prices. For instance, freelancers from developed countries complained about the differences between living costs that allow freelancers from developing countries to offer lower prices. Similarly, freelancers from developing countries disliked clients expecting to pay only a few dollars for their services. Moreover, workers described the need to be "always online" checking for updates and trying to catch the best job opportunities. In this regard, given the number of applications received by clients, many freelancers told us they had to continuously 
Forthcoming Journal of Managerial Psychology

PLEASE DO NOT DISTRIBUTE WITHOUT AUTHORS'PERMISSION

write new proposals for clients and reply swiftly to their questions, being locked in a continuous commitment to the platform, as shown in the following excerpt:

"You have to keep applying for the jobs once they are posted, so you have to check constantly posts and job opportunities. You have to stay online, and once you are online you need to ensure that you are there for a long time. That is why we just work for four days in a week. You burn-out faster."

[Brian, IT developer]

Acquiring knowledge of the market. Contrary to what happens in offline contexts, the online platform provides public information on the main actors of the market. We found that this platform's feature was positively valued by freelancers. Many informants strategically used this public information to acquire knowledge on both job demands and their competitors' behaviors. Many respondents told us that, especially at the beginning of their presence on the platform, they surfed other freelancers' public profiles and studied the characteristics of the offered services, the typical price for that service, and general competitors' strategies. This practice was useful to learn about prototypical services and skills sold on the platform.

Becoming a unique online worker. We found that dealing with competition by comparing oneself with other people on the platform was useful to align to market's requests. Many informants declared, indeed, that surviving on the platform would have been much harder without a clear understanding of how other people behaved on the platform. For instance, knowing competitors' strategies was useful to guess about clients' expectations and start to think about how to meet those expectations. However, in order to obtain jobs, individuals also needed to think and understand what made them different from other freelancers. The need to distinguish oneself from others made freelancers think deeply about the distinctive skills and traits that characterized themselves as professionals. For instance, in the following excerpt, one respondent from a 
Forthcoming Journal of Managerial Psychology PLEASE DO NOT DISTRIBUTE WITHOUT AUTHORS'PERMISSION

developed country shared how he tried to distinguish himself from gig workers from emergent countries.

"There is really heavy competition from people from India, Philippines, Mexico, mostly these. And they work for really low prices, it is hard to compete with them. So I needed to think: what can I do that these guys cannot do? My first job was in translating between Portuguese and English, which is something I do well and they cannot do." [Sean, IT developer]

Short-term contracts, Trying to Sell Skills, and Becoming your own Sponsor Short-term contracts. Gig workers needed to deal with the intrinsic uncertainty in their work related to the short-term nature of working relationships. For instance, translators and web site developers complained about the difficulty of establishing long-term relations with clients, and perceived this as a constraint. For instance, they explained that usually clients posted jobs to be delivered on a daily basis, making relations difficult to build. Thus, a crucial aspect was the need to constantly search for new jobs. Informants working exclusively online needed to allocate time to both the monitoring of new offers on the platform and the hiring process itself, which usually included one or more job interviews. Therefore, they needed to be "constantly prepared to answer clients' questions", as hiring procedures were constantly ongoing. Informants usually reported frustration and feelings of job insecurity and needed to rationalize uncertainty as an inherent characteristic of their job. The following excerpt shows one of our informants recognizing uncertainty in her job, and explaining that reducing uncertainty was her main goal on the platform:

"My job is completely uncertain. The main objective is to get you into a point where is not uncertain anymore. I think it is right now my main goal. Because you get one job, and then you get different jobs, and you get one job again, you need to deal with the fact that you will need to get them."

[Heather, IT developer] 
Forthcoming Journal of Managerial Psychology PLEASE DO NOT DISTRIBUTE WITHOUT AUTHORS' PERMISSION

Trying to sell skills. To manage the fast-paced hiring process, the platform provides technological features that can be used to present workers to clients, i.e. personal profiles and job proposals. Personal profiles can be filled with information on employment history, educational background, working history on the platform, and brief personal descriptions. Job proposals are letters sent to clients and usually represent the first interaction between freelancers and clients. When asked to detail the strategies to win a job, respondents provided us with a description of job proposals and personal profiles, describing them as fundamental tools to sell their skills. In particular, we found profiles to be used to provide references, and job proposals to fit job calls. In the following excerpt, one informant described how clients looked at profiles and how having good reviews was essential at the beginning of his career:

"I think that when clients look at your profile, they first see your grade, they don't really check anything else. And if they see that your grade is good, then they check your portfolio. So basically it's a few step thing, if you don't have good grade they will not even look at your portfolio.” [Brad, Designer]

As exemplified in the quote, profiles were perceived as digital signals of reputation (grades) and digital proofs of experiences (portfolio). In addition, freelancers used proposals to show the fit between their portfolio and job calls, in order to convince clients about their capability to fulfill job requests. The following quote exemplifies this strategy and shows another recurrent best practice: when presenting one' skills, freelancers should try to sell also additional skills. "I try, in my proposal, to make it short enough as not to bore the person, and I try to answer the questions that the person is asking. By doing that, the person knows that I have read the offer. [...] After reading the job offer, I explain how I can address his concerns. This gives who is hiring some extra pieces of mine and a bit of extra to what he asks". [Sean, IT developer] 
Forthcoming Journal of Managerial Psychology PLEASE DO NOT DISTRIBUTE WITHOUT AUTHORS'PERMISSION

Becoming your own sponsor. We found that dealing with the fast-paced hiring process and selling individual skills were capabilities that freelancers needed to learn. For instance, especially when first joining the platform, building a strong portfolio and a strong reputation were essential to getting jobs and surviving on the platform, as one of our informants described in the following excerpt:

"At the beginning, I really wanted to get as much reviews as possible to be able to bid some other jobs that I couldn't get without reviews, so at first it wasn't really about the money, it was about catching the reviews.”[Brad, Designer]

Freelancers described that they needed to experiment with different job proposals before finding the right strategy, and this usually entailed acquiring additional knowledge on how to deal with clients and promote their own individual skills. Some freelancers started to think about themselves as professionals who should also successfully promote their work, not just search for gigs.

Many freelancers described how they started to focus more and more on empowering their communication and negotiating skills in addition to their technical skills. This, in turn, led them to think about themselves as good communicators or good negotiators, as shown by the quote below:

"I found out that clients were interested not only in my professional skills as a designer, but also on my negotiating and communicating capabilities, on who I am as a negotiator and communicator.” [Adam, Designer]

Lack of Support, Experimenting with Different Opportunities, and Becoming your own Boss Lack of Support. We asked freelancers about the role played by the platform in supporting their daily activities. Answers revealed that they considered the platform as a third party, a service they used exclusively for finding jobs, delivering their work, and being paid. In the perspective 
Forthcoming Journal of Managerial Psychology

PLEASE DO NOT DISTRIBUTE WITHOUT AUTHORS'PERMISSION

of our informants, the platform environment did not provide the direct guidance or mentorship that is typical of traditional organizational contexts. We analyzed archival documents to assess the design of the platform environment with a special focus on the features intended to provide support to gig workers. We learned that the platform sends tips and advice to freelancers through reports or blog articles describing the experience or the strategies to become a successful online freelancer. However, during interviews we found that only a few respondents read and tried to follow those tips. Many respondents replied that they lacked the time to read newsletters, while others admitted to searching for tips on other websites, or looking for advice from friends. One respondent even judged negatively the perceived lack of targeted advice and expressed the willingness to distinguish himself from those following the platform's general tips. We thus labeled the perception of the platform's guidance as superficial. The following excerpts exemplify these recurrent perceptions:

"Apart from the platform itself they [the platform staff] do not offer any kind of training or tools, or something like that. [...] ...there is no any tutorial that will help freelancer succeed." [Scott, database administrator]

“... they already have help pages, support pages and all that...but, who reads that?! Like, who reads that?! I don't, because what they have done is very short, not very descriptive." [Nancy, IT developer]

Experimenting with different opportunities. If on the one hand freelancers lacked clear guidance, on the other hand the platform offered them a variety of job opportunities. Many freelancers subscribed to the platform for the purpose of reaching out to clients from other countries and finding more jobs related to their skills. For instance, a game developer lamented difficulties in finding game development-related jobs in the "traditional" job market. In addition, many Asian IT developers experienced difficulties in selling their specific knowledge in the local market, 
Forthcoming Journal of Managerial Psychology PLEASE DO NOT DISTRIBUTE WITHOUT AUTHORS'PERMISSION

both for the lack of opportunities and the low payments. Thus, we noticed how freelancers were using the platform to sustain their learning experience and how some of them also started to use their profile to convey not only skill-related information, but also information on plans for the future and on the next jobs they would like to deliver. The following excerpt is drawn from one IT developer's profile description and illustrates the described behavior:

"I now seek ongoing jobs that will help me shift from front-end to back-end, and from [programming language 1] to [programming language 2].” [Sean, IT developer, personal profile]

Moreover, informants explained that the huge number of job calls posted on the platform left them room for trial and error. In fact, thanks to plenty of opportunities, they could try to apply for different jobs while at the same time trying out different strategies to get a job, even strategies that later became unsuccessful. As they knew other desirable job opportunities would soon materialize, they felt they had the time to try to deal with clients and learn how to obtain jobs without the fear of making errors and missing desirable job opportunities.

Becoming your own boss. The lack of a boss deciding on their work and the availability of variegated opportunities gave gig workers, especially once they obtained a good reputation, the freedom to choose the jobs to be delivered. As shown in the following excerpt, IT developers strategically chose jobs to keep on learning, avoid getting bored by doing the same activities over and over, and stay updated with the latest technology.

"I'm actually getting even greater experience, because in firms you do not get to deal with the client himself, obviously the boss deal with them. Here, I'm my own boss [...] So, in the firm your boss sells the company, the products, and everything, you are just involved in the development of the product, you are not actually on the field, you are not actually dealing with the client, you are not actually knowing the client's requirements from the client. So, in here I get to talk to the client, I get to understand the requirements of the clients." [Nancy, IT developer] 
Forthcoming Journal of Managerial Psychology

PLEASE DO NOT DISTRIBUTE WITHOUT AUTHORS'PERMISSION

Our informants talked more often about the managerial skills they needed to learn to deal with the platform environment, negotiate payments, and organize their working day, than the technical skills required to deliver clients' jobs. They explained how they unexpectedly found themselves occupied in managing their business, as described in the following excerpt.

"I like having my own office, I am my own boss. It is better than working for someone else, you can organize finances, you can discuss about payments with your clients directly, there's no one inbetween" [Trevor, IT developer]

\section{Development of an Entrepreneurial Orientation}

We found that freelancers' experiences on the platform ultimately influenced their way of thinking about themselves in the workplace. After some time spent on the platform, respondents generally described themselves as more conscious about what was needed to be successful online freelancers. The following excerpts report a respondent's feelings:

"You go there with your skills, with what you are doing, and the platform gives you the opportunity to sell them. But I realized that, in the end, it is your own responsibility, you have the responsibility of how to do that [selling the skills]. I feel like I have built a real job there" [Kate, Designer]

As shown in the quote, we found that online behaviors ultimately influenced an individual's job-related sense of self, desires for the future, and perceptions regarding the platform itself. More generally, we found that the process of work identity construction, influenced by the constraints of the environment and the strategic use of technological features, led individuals to distance themselves from both traditional organizations and online labor markets. We noticed then that respondents were talking about their online experience as an evolution that led many of them to the development of an entrepreneurial orientation, i.e. to develop practices, processes and decision making behaviors aimed at building a new entrepreneurial 'entity' (e.g. a new group or a new organization, Lumpkin and Dess, 1996). This evolution is well shown by an informant's 
Forthcoming Journal of Managerial Psychology PLEASE DO NOT DISTRIBUTE WITHOUT AUTHORS' PERMISSION

job applications, provided in Figure 3. Kate, one of our informants, shared with us three different job applications written at different stages of her experience on the platform. As is shown in the figure, in job application 1 she only describes her distinctive characteristics, then, in job application 2, she adds details to sponsor her work, like her personal web site, and in job application 3 she finally describes herself as the head of a team.

---- Insert Figure 3 about here ----

We linked emergent freelancers' behaviors to three of the five entrepreneurial orientation's dimensions identified by Lumpkin and Dess (1996). In particular, we recognized the dimensions of competitive aggressiveness, autonomy, and proactiveness in the way freelancers positioned themselves in the market, distanced themselves from the platform, and created their own businesses.

Aggressively competing to position oneself on the market. As the competition becomes global, freelancers need to find their own way to stand out and convince clients they can fit their needs. If, on the one hand, the availability of information on the platform was useful to align to market requests, at the same time, it helped freelancers to set their own services and their own prices on the market, according to what they thought were their distinctive traits. This not only allowed freelancers to set their competitive strategy, but also to try to catch the attention of a particular subset of clients interested in some services rather than others, in some standards of quality rather than others. In other words, freelancers worked hard to win a particular segment of the online labor market. For instance, in the quote below, Harry describes his willingness to be perceived as a valuable worker, and the decision to set higher prices on the market to communicate this information to clients.

"I am not cheap, I am sorry. I am a valuable worker, I am a valuable freelancer. I am not like many other freelancers that decide to work at low prices." [Harry, designer] 
Strengthening the Importance of Autonomy. We found that managing themselves on the platform strengthened freelancers' attitudes towards autonomy. Those searching for more freedom in their job valued autonomy as a positive and essential element in their work. However, surprisingly, we noticed that even freelancers who initially thought about the platform as a playground to test their skills, strengthen their curriculum, and then go back to traditional work, struggled to think about themselves as merely employees within a company. In particular, they positively valued the opportunity to learn and choose exciting jobs for themselves, opportunities they could barely see when employed in a company. Freelancers who joined the platform to gain extra money showed similar feelings. We thus noticed a tendency to value and retain autonomy from the online experience and then to change the perceptions of traditional working environments. As shown in the following excerpt, informants rarely told us they would prefer to go back to a traditional job after their experience on the platform:

"Right now, I wouldn't really want to go back to a traditional job, you know? Because I would very much prefer other things and build things myself." [Denise, IT developer]

We noticed that being independent from a traditional organization gradually grew into the idea of becoming independent from the platform too. Informants described the platform as an "intermediate land" useful to acquire competencies, experiment and test skills, and quickly get in touch with multiple clients and job opportunities. However, many freelancers did not describe it as the place to be for a long time. On the contrary, they seemed to interpret their time on the platform as a transitional period in their career. In other words, instead of identifying with the platform, they rather seemed to feel disaffected from it over time. Interestingly, one of our informants described the platform as an "incubator", thus as an entity accelerating the growth process of a nascent company. 
Forthcoming Journal of Managerial Psychology

PLEASE DO NOT DISTRIBUTE WITHOUT AUTHORS'PERMISSION

"I don't anticipate staying on [name of platform] forever, [name of the platform] is kind of an incubator where I am gaining competencies, I am dealing with people, and building up my portfolio." [Grace, designer]

Proactively creating one's own business. After some time spent on the platform, instead of thinking about themselves just as freelancers, many informants expressed their desire to build their own company or a new business within or outside of the online environment. Their objective was to leverage their experience on the platform for building a local team and starting to work with local clients. For instance, in the following excerpt, one informant explained how being successful on the platform led him to switch to an entrepreneurial role:

"I took the option of the freelancer, and I am happy with this decision and it is going well. During the last six months of my career in 2010, I ended up deciding my role. I could have been an entrepreneur instead of only a single freelancer. So, I have decided and I took the option of creating a local team. Then, I created a team profile on [platform], whose name is The Helper, that is also the nature of our job. [...] I have constructed myself a successful freelancer, that is why I have created a team, I have worked on that for years. Those things made me a successful freelancer entrepreneur." [Alec, virtual assistant]

Similarly, other informants described their willingness to shift into managerial roles, and their willingness to possibly hire either local or online employees:

"We are a group of friends who were also freelancers and we are actually sharing our resources to create a small start-up, so you can say we are moving to a managerial part and then hiring developers locally who will handle the work for us, and we will be mostly the managers." [Jamey, IT developer] "I am a contractor now, but I want to become a client next year. I am trying to turn myself a client, this means more personal satisfaction and more income. I would like to be an entrepreneur in the next 3 or 4 years, I see myself as an entrepreneur". [Ken, Translator] 
Forthcoming Journal of Managerial Psychology

PLEASE DO NOT DISTRIBUTE WITHOUT AUTHORS'PERMISSION

Finally, others reported their desire to leverage their experience on the platform to build companies, either related to online work or not.

"Even though we just communicate with clients through online platforms, it really helps us grow more, even though we are at home. [...] Actually, my goal is to start a company for helping other companies to implement online work, because I think this is going to be a really great opportunity in the next 5 years." [Rachel, virtual assistant]

\section{Discussion}

The purpose of this study was to explore the experience of gig workers in technology-mediated working domains - i.e. online labor markets - to shed light on how technology is related to their work identity. Our model shows how workers' work identity underwent a process of construction in response to a constraining online environment, by strategically using platform resources. Freelancers joined online labor markets to fulfill different needs, from the necessity to work remotely to the desire to gain extra money. Once on the platform, they needed to face the difficulties of working online (i.e. global competition, short-term contracts, lack of guidance) and thus learn how to leverage technological resources offered by the platform (i.e. public information on competitors' actions, profiles and job proposals, multiple job opportunities). We showed that each constraint of the platform environment, overcome by a strategic use of technological features, led freelancers to work on their own skills and on their individual work identity. In particular, they needed to focus on their unique personal characteristics to become distinctive and stand out as online workers. They also had to learn how to sell their skills and competencies to clients, thus thinking about themselves as sponsors of their own work. Finally, they had to shift to a managerial mindset and self-envision as boss of themselves, that is, they needed to switch from considering themselves as freelancers or contractors (e.g. Barley and Kunda, 2006) to seeing themselves as the head of their own business. This led to the 
Forthcoming Journal of Managerial Psychology

PLEASE DO NOT DISTRIBUTE WITHOUT AUTHORS'PERMISSION

development of an entrepreneurial orientation, characterized by competitive aggressiveness, autonomy, and proactivity. This shift can be illustrated by their decision to offer new services, by their desire to be independent both from the platform and from traditional labor markers, and by their willingness to create and supervise teams, to open 'agency profiles' on the platform, or to envision a future outside the platform as start-ups.

\section{Technology and Work Identity Expansion}

Our research was motivated by an interest in the process of work identity construction for gig workers. While traditionally organizations and professions contribute to work identity construction, people working in uncertain conditions are likely to search for different sources of stability influencing identity construction (Petriglieri et al., 2018). The paper theorizes about the fundamental role of technology in such a process. In particular, we noticed that the technology, i.e. the platform, triggered an experiential process of work identity construction instead of breaking meanings and influencing subsequent new definitions (Alvesson et al., 2008; Ashforth and Schinoff, 2016; Pratt, 2000). Through experimenting with the platform, freelancers develop an entrepreneurial mindset by integrating into their work identities pieces of self as unique workers, sponsors, and bosses. This process differs substantially from the current understanding we have about how freelancers or contractors work on their identities. While current studies (e.g. George and Chattopadhyay, 2005; Petriglieri et al., 2018) suggest that these workers will look for substitutes for organizational environments by developing other types of holding environments that sustain current meaning and identities, our research underlines that in a technology-mediated context that provides sharp constraints but also some resources, workers may end up developing new components of the self that they did not envision when they first joined the online environment. This idea is supported by the efforts put in place by freelancers in 
developing meanings of themselves not as professionals in a technical domain (i.e. reinforcing their identity as designers or IT developers), but as professionals who also need to sponsor their work, communicate with clients, and run their business, therefore acting as entrepreneurs.

Thus, we propose to expand the sources available for crafting work identity by including online work environments, such as platforms for online labor markets. Given the increasing prevalence of online resources, communities, and collaborative technologies that professionals use, it is important to consider the different technological environments individuals experience at work if we want to fully comprehend their individual work identity and consequently how they may behave in online, as well traditional, workplaces.

In addition, we extend the current scholarly conversation on the relation between identity and technology that until now has primarily looked at technology (in our study online platform) as a set of features that impact work identity (e.g. Van Akkeren and Rowlands, 2007; Boudreau et al., 2014; Stein et al., 2013) and only secondarily as an enabler of different contexts embedding an online component (e.g. Moon et al., 2006), which means new rules of the game for people who participate (here online labor markets). We combined, then, the perspective of technology as a set of features and technology as an online environment, and showed that the platform constrained individuals in an uncertain online environment, but also offered technological features to manage and rationalize uncertainty. We thus support the idea of a closer relation between technology and identity where, in the presence of technology, the self is expanded to include capabilities afforded by the IT (Carter and Grover, 2015). In particular, we see high levels of dependence and relatedness (Carter and Grover, 2015), especially in the first periods of engagement with the platform. However, differently from Carter and Grover's (2015) perspective, we do not see enduring feelings of attachment towards the technology, as in our case 
the technology-triggered work identity seems to lead individuals away from the technology itself. Indeed, our findings show that freelancers tend to distance instead of commit to the platform after some time spent there, as the development of an entrepreneurial orientation may take them back to more traditional and local labor markets. Building on the notion of IT identity (Carter and Grover, 2015), we thus propose that a definition of self as dependent from technology might be temporal. As suggested by the metaphor of platforms as incubators provided by one of our informants, we propose technology as essential for growth and selfexpansion, but whose benefits might be limited to workers' early stages of career or first periods of engagement with the technology itself.

\section{Emergent Entrepreneurial Orientation}

As an emergent contribution, we think our findings are consistent with a few recent studies showing accidental pathways towards entrepreneurial activities (Demetry, 2017; Garcia-Lorenzo et al., 2018). Our model shows what initially motivated our informants to engage in online work. Specifically, these motives are related to monetary compensation, fun, work flexibility, learning, and stagnant local labor markets. These reasons have little to do with the desire to start up a company or become an entrepreneur. Indeed, none of our informants seemed to be initially focused on developing entrepreneurial skills, neither expressing the desire to build their own company, or even simply imagining themselves as entrepreneurs in the future. However, after experiencing and learning how to navigate the platform, we found that many of our freelancers developed entrepreneurial orientations.

According to Lumpkin and Dess (1996), entrepreneurial orientation "refers to the processes, practices, and decision-making activities that lead to new entry" (Lumpkin and Dess, 1996, p. 136) and "it involves the intentions and actions of key players functioning in a dynamic 
Forthcoming Journal of Managerial Psychology

PLEASE DO NOT DISTRIBUTE WITHOUT AUTHORS'PERMISSION

generative process aimed at new-venture creation" (Lumpkin and Dess, 1996, pp. 136-137).

Entrepreneurial orientation consists of five dimensions: competitive aggressiveness, risk taking, innovativeness, autonomy, and proactiveness. Our evidence shows that, in the context of online labor markets, gig workers developed an entrepreneurial orientation as they started to define new services to capture a new market segment (competitive aggressiveness), valued their independence from any labor market (autonomy), and created agency profiles, local teams, or start-ups (proactiveness). Consistent with the model proposed by Lumpkin and Dess (1996), which emphasizes that dimensions can vary independently in different contexts, we show that the platform triggers three out of the five dimensions of entrepreneurial orientation through the interplay between a constraining online environment and the freelancers' strategic use of technological features. Therefore, our theory extends that model by proposing that technology use should be considered within the set of drivers influencing entrepreneurial orientations and by identifying the online labor platform as a specific context that creates the conditions for entrepreneurial orientation to emerge. These reflections are also consistent with the study by Autio and colleagues (2013), who examined how the exposure to multiple information and interactions with peers on an online community supported the reduction of uncertainty embedded in the process of business creation and helped individuals to both discover new business opportunities and also to take entrepreneurial actions.

We further argue that our informants developed an entrepreneurial orientation in reaction to their experience and emerging behaviors on the platform, rather than as result of a pre-defined plan (e.g. Krueger, 1993; Krueger et al., 2000). Our findings are coherent with the idea of entrepreneurship as an emergent process (Demetry, 2017) and business creation as the result of a series of actions, rather than a onetime act (Demetry, 2017; Ruef, 2010). Rather than intentional, 
Forthcoming Journal of Managerial Psychology

PLEASE DO NOT DISTRIBUTE WITHOUT AUTHORS' PERMISSION

pathways to entrepreneurship might be accidental (Demetry, 2017). Necessity and liminal conditions may trigger the emergence of entrepreneurship (Garcia-Lorenzo et al., 2018).

To this regard, our findings build on and extend the work of Farmer and colleagues (2011), who described the emergence of entrepreneurial behaviors as influenced by entrepreneur identity aspiration. In accordance with their work, our data suggest that work identity can influence subsequent behaviors. For instance, many of our informants opened agencies or started to manage teams on online labor markers. In addition, our evidence also shows that these actions can influence cognitions, as we found that the development of the entrepreneurial orientation was the result of entrepreneurial oriented behaviors practiced on the platform instead of a planned behavior. In other words, we argue that the work identity extended through the experience on the platform influences subsequent behaviors, and that these behaviors are ultimately associated to a more entrepreneurial mindset.

\section{Implications for Practice}

Our study contributes to a better understanding of how gig workers enact the working environment provided by a platform and, in particular, how this environment influences individual self-perceptions and identity. First, as we found that freelancers need to become unique online workers and position on the market, we suggest that platform providers could act as labor advisors by periodically sharing information on the new skills required on the market, as for example building analytics for IT developers. This practice would allow freelancers to easily understand what are the main skills required by the market, and help them target and conquer their market share, either by strengthening existing or developing new skills. 
Forthcoming Journal of Managerial Psychology PLEASE DO NOT DISTRIBUTE WITHOUT AUTHORS'PERMISSION

Second, as we found that freelancers need to become sponsors of their work, we encourage platform providers to develop feedback mechanisms for evaluating not only the quality of delivered work, but also the way freelancers present to clients and sponsor their work. This could be done, for instance, by asking the client to rate the job applications they receive or the profile of freelancers they are interested in hiring. Such information could allow freelancer to gather more knowledge about clients' expectations and help them lower the number of job applications' rejections, especially when they are new to the platform.

Finally, as freelancers become their own bosses, we suggest that platform providers begin to develop mechanisms for assisting in a new job search or for filtering the requests received by freelancers. For instance, platforms could create filters and criteria for helping them to automatically withdraw job requests they are not interested in. Similarly, we would encourage the creation of automated filters and mechanisms for suggesting freelancers job calls that respond to their specific needs, in order to lower the time spent in job searches and, eventually, replying more quickly to clients and increasing the likelihood of being hired, especially for newcomers. In addition, platforms could also build a freelancer's dashboard to help monitor their performance on the platform, such as jobs where they were particularly successful or not and why. This could allow them to focus and improve those dimensions in which they had been less successful, adjusting their behaviors according to client's needs.

By taking these (and perhaps other) actions, we believe the platform could improve the quality of workers' experiences on the platform, therefore incentivizing more workers to actually stay on the platform, especially those who might feel safer working in a helpful environment instead of being on their own or taking the risk associated with a company. Indeed, as we acknowledge the emergence of an entrepreneurial orientation, freelancers could also exploit it 
through the platform, for instance by starting to hire themselves contractors on the platform and collaborate with them to make their business grow. On the other hand, we also suggest that platform providers could extend their services to those willing to expand their business, for instance by creating networking systems that allow freelancers interested in working in a team or launching a start-up to meet people with different, complementary skills, and put in place mechanisms to help them collaborate at a distance. In this regard, platforms could offer their workers online front-end spaces for networking and back-end collaboration spaces to foster the emergence of teams (and perhaps companies). This would allow nascent entrepreneurs to collaborate in an international environment, instead of only locally through personal networks. Furthermore, platforms could create customized fees for those who had worked on the platform for a long period of time and who finally decide to open an agency profile and continue to catch clients on the platform. This would allow the platform to act more as an incubator and, at the same time, support nascent entrepreneurs without completely losing earnings derived from fees. If these actions were taken, the platform itself could diversify the services offered to different types of workers, and workers could more easily choose what their relation with the platform should be.

\section{Limitations and Future Research Directions}

Our study is not of course without limitations. To explore how individuals build their identity, we sampled individuals who succeeded on the platform and did not address those who did not adapt well to the platform's mechanisms. In addition, we only sampled people from some professions and some nationalities. Therefore, to have a complete picture of gig workers' 
experiences, one should also include unsuccessful examples and understand if individuals in different professions may experience different identity work patterns.

Furthermore, we drew evidence from a single online platform, so our results may suffer from the influence of that platform's specific mechanisms. We thus encourage further investigation of different platform mechanisms to acknowledge whether they trigger similar or different identity processes.

Finally, we encourage future studies to develop a deeper understanding of how the unique context of online labor market platforms moderates the relationships between entrepreneurial intentions and behaviors. Specifically, with regard to proactiveness and the creation of a new business, our findings reveal that the online platforms triggers different behaviors, starting from expressing the desire to build a new company or build a local team, to building an actual local team, hiring other freelancers online to deliver subsets of jobs, or creating a business. This suggests that the platform enables entrepreneurial actions, but this emergent issue has not been explored in detail in this study. A valuable extension of our research, that testifies how entrepreneurial orientation is reflected in a set of behaviors, could detail which contextual factors of the online labor markets or personal motives guide individuals towards the enactment of these different behaviors and why, contributing to the current debate on the role of social and contextual factors in translating entrepreneurial intentions into actions (e.g. Fini et al., 2012; Meoli et al., 2017). We also suggest that researchers interested in these topics should continue to follow the activities of emergent entrepreneurs to acknowledge whether the context of online labor markets triggers successful or unsuccessful entrepreneurial activities.

\section{References}


Van Akkeren, J. and Rowlands, B. (2007), "An epidemic of pain in an Australian radiology practice", European Journal of Information Systems, Vol. 16, pp. 695-711.

Alvesson, M., Ashcraft, K.L. and Thomas, R. (2008), "Identity matters: reflections on the construction of identity scholarship in organization studies", Organization Studies, Vol. 15 No. 1, pp. 5-28.

Ashford, S.J., Caza, B.B. and Reid, E.M. (2018), "From surviving to thriving in the gig economy: A research agenda for individuals in the new world of work", Research in Organizational Behavior, Elsevier available at:https://doi.org/10.1016/j.riob.2018.11.001.

Ashford, S.J., George, E. and Blatt, R. (2007), "2 Old Assumptions, New Work”, The Academy of Management Annals, Vol. 1 No. 1, pp. 65-117.

Ashforth, B.E. and Schinoff, B.S. (2016), "Identity Under Construction: How Individuals Come to Define Themselves in Organizations", Annual Review of Organizational Psychology and Organizational Behavior, Vol. 3, pp. 111-137.

Autio, E., Dahlander, L. and Frederiksen, L. (2013), "Information Exposure, Opportunity Evaluation, And Entrepreneurial Action: An Investigation of An Online User Community", Academy of Management Journal, Vol. 56 No. 5, pp. 1348-1371.

Barley, S., Bechky, B. and Milliken, F. (2017), "The changing nature of work: Careers, identities, and work lives in the 21st century", Academy of Management Discoveries, Vol. 3 No. 2, pp. 111-115.

Barley, S.R. and Kunda, G. (2006), "Contracting: A New Form of Professional Practice", Academy of Management Perspectives, Vol. 20 No. 1, pp. 45-66.

Behrend, T.S., Sharek, D.J., Meade, A.W. and Wiebe, E.N. (2011), "The viability of crowdsourcing for survey research", Behavior Research Methods, Vol. 43 No. 3, pp. 800813.

Boudreau, J., Jesuthasan, R. and Creelman, D. (2015), Lead the Work: Navigating a World beyond Employment, edited by Wiley, San Francisco.

Boudreau, K.J. and Lakhani, K.R. (2013), "Using the crowd as an innovation partner", Harvard Business Review, Vol. 91 No. 4, pp. 60-69.

Boudreau, M.C., Serrano, C. and Larson, K. (2014), "IT-driven identity work: Creating a group identity in a digital environment", Information and Organization, Elsevier Ltd, Vol. 24 No. 1 , pp. 1-24.

Cappelli, P. and Keller, J. (2013), "Classifying Work in the New Economy", Academy of Management Review, Vol. 38 No. 4, pp. 575-596.

Carter, M. and Grover, V. (2015), "Me, Myself, and I(T): Conceptualizing Information 
Technology Identity and Its Implications”, MIS Quarterly, Vol. 39 No. 4, pp. 931-957.

Carton, G. and Ungureanu, P. (2018), "Bridging the Research-Practice Divide: A Study of Scholar-Practitioners' Multiple Role Management Strategies and Knowledge Spillovers Across Roles", Journal of Management Inquiry, Vol. 27 No. 4, pp. 436-453.

Connelly, C.E. and Gallagher, D.G. (2004), "Emerging trends in contingent work research", Journal of Management, Vol. 30 No. 6, pp. 959-983.

Demetry, D. (2017), "Pop-Up to Professional: Emerging Entrepreneurial Identity and Evolving Vocabularies of Motive", Academy of Management Discoveries, Vol. 3 No. 2, pp. 187-207.

Deng, X., Joshi, K.D. and Gelliers, R.D. (2016), “The Duality of Empowerment and Marginalization in Microtask Crowdsourcing: Giving Voice To the Less Powerful Through Value Sensitive Design”, MIS Quarterly, Vol. 40 No. 2, pp. 279-302.

Dutton, J.E., Roberts, L.M. and Bednar, J. (2010), "Pathways for positive identity construction at work: Four types of positive identiy and the building of social resources", Academy of Management Review, Vol. 35 No. 2, pp. 265-293.

Farmer, S.M., Yao, X. and Kung-Mcintyre, K. (2011), “The Behavioral Impact of Entrepreneur Identity Aspiration and Prior Entrepreneurial Experience", Entrepreneurship Theory and Practice, Vol. 35 No. 2, pp. 245-273.

Fini, R., Grimaldi, R., Marzocchi, G.L. and Sobrero, M. (2012), “The Determinants of Corporate Entrepreneurial Intention Within Small and Newly Established Firms", Entrepreneurship: Theory and Practice, Vol. 36 No. 2, pp. 387-414.

Furnham, A. (2006), "Work in 2020. Prognostications about the world of work 20 years into the millennium”, Journal of Managerial Psychology, Vol. 15 No. 3, pp. 242-254.

Garcia-Lorenzo, L., Donnelly, P., Sell-Trujillo, L. and Imas, J.M. (2018), "Liminal Entrepreneuring: The Creative Practices of Nascent Necessity Entrepreneurs", Organization Studies, Vol. 39 No. 2-3, pp. 373-395.

Gecas, V. (1982), “The Self-Concept”, Annual Review of Sociology, Vol. 8, pp. 1-33.

George, E. and Chattopadhyay, P. (2005), "One Foot in Each Camp : The Dual Identification of Contract Workers", Administrative Science Quarterly, Vol. 50 No. 1, pp. 68-99.

Gioia, D.A., Corley, K.G. and Hamilton, A.L. (2013), "Seeking Qualitative Rigor in Inductive Research”, Organizational Research Methods, Vol. 16 No. 1, pp. 15-31.

Glaser, B. and Strauss, A. (1967), The Discovery of Grounded Theory, Weidenfield \& Nicolson, London.

Hollister, M. (2011), "Employment Stability in the U.S. Labor Market: Rhetoric versus Reality", Annual Review of Sociology, Vol. 37 No. 1, pp. 305-324.

Horton, J.J., Rand, D.G. and Zeckhauser, R.J. (2011), “The online laboratory: Conducting 
Forthcoming Journal of Managerial Psychology

PLEASE DO NOT DISTRIBUTE WITHOUT AUTHORS'PERMISSION

experiments in a real labor market”, Experimental Economics, Vol. 14 No. 3, pp. 399-425.

Ibarra, H. (1999), "Provisional Selves: Experimenting with Image and Identity in Professional Adaptation", Administrative Science Quarterly, Vol. 44 No. 4, pp. 764-791.

Ibarra, H. and Obodaru, O. (2016), "Betwixt and between identities: Liminal experience in contemporary careers", Research in Organizational Behavior, Elsevier Ltd, Vol. 36, pp. $47-64$.

Irani, L. (2015), “The cultural work of microwork", New Media \& Society, Vol. 17 No. 5, pp. $720-739$.

Kapelner, A. and Chandler, D. (2010), "Preventing satisficing in online surveys : A 'kapcha' to ensure higher quality data", Information Systems Journal, No. June, pp. 1-10.

Koppman, S., Mattarelli, E. and Gupta, A. (2016), “Third-World 'Sloggers' or Elite Global Professionals? Using Organizational Toolkits to Redefine Work Identity in Information Technology Offshore Outsourcing”, Organization Science, Vol. 27 No. 4, pp. 825-845.

Krueger, N. (1993), "The Impact of Prior Entrepreneurial Exposure on Perceptions of New Venture Feasibility and Desirability", Entrepreneurship Theory and Practice, Vol. 18 No. 1, pp. 5-21.

Krueger, N.F., Reilly, M.D. and Carsrud, A.L. (2000), “Competing models of entrepreneurial intentions", Journal of Business Venturing, Vol. 15 No. 5, pp. 411-432.

Kuhn, K.M. and Maleki, A. (2017), "Micro-entrepreneurs, dependent contractors, and instaserfs: Understanding online labor platform workforces", Academy of Management Perspectives, Vol. 31 No. 3, pp. 183-200.

Lam, C.F., Liang, J., Susan, A.J. and Lee, C. (2015), "Job Insecurity and Organizational Citizenship Behavior: Exploring Curvilinear and Moderated Relationships”, Journal of Applied Psychology, Vol. 100 No. 2, pp. 499-510.

Lamb, R. and Davidson, E. (2005), "Information and Communication Technology Challenges to Scientific Professional Identity”, The Information Society, Vol. 21 No. 1, pp. 1-24.

Langner, B. and Seidel, V.P. (2015), "Sustaining the flow of external ideas: The role of dual social identity across communities and organizations", Journal of Product Innovation Management, Vol. 32 No. 4, pp. 522-538.

Lumpkin, G.T. and Dess, G.G. (1996), "Clarifying the Entrepreneurial Orientation Construct and Linking it to Performance”, Academy of Management Journal, Vol. 21 No. 1, pp. 135-172.

Mason, W. and Suri, S. (2012), "Conducting behavioral research on Amazon's Mechanical Turk”, Behavior Research Methods, Vol. 44 No. 1, pp. 1-23.

Mattarelli, E. and Tagliaventi, M.R. (2015), "How Offshore Professionals' Job Dissatisfaction Can Promote Further Offshoring: Organizational Outcomes of Job Crafting”, Journal of 
Management Studies, Vol. 52 No. 5, pp. 585-620.

Meoli, A., Wiklund, J., Fini, R. and Sobrero, M. (2017), "Entrepreneurial Intention and Action: Social Influences as the Missing Link", Academy of Management Proceedings, Vol. 2017 No. 1, p. 14352.

Moon, J., Pu Li, J., Jo, S. and Sanders, G.L. (2006), "Improving Quality of Life via Blogs and Development of a Virtual Social Identity", Journal of Information Technology Management, Vol. XVII No. 3, pp. 26-37.

Paolacci, G., Chandler, J. and Ipeirotis, P. (2010), "Running experiments on amazon mechanical turk", Judgment and Decision Making, Vol. 5 No. 5, pp. 411-419.

Petriglieri, G., Ashford, S.J. and Wrzesniewski, A. (2018), "Agony and Ecstasy in the Gig Economy: Cultivating holding environments for precarious and personalized Work identities", Administrative Science Quarterly.

Petriglieri, G. and Petriglieri, J.L. (2010), "Identity workspaces: The case of business schools", Academy of Management Learning and Education, Vol. 9 No. 1, pp. 44-60.

Pratt, M.G. (2000), "The Good, the Bad, and the Ambivalent: Managing Identification among Amway Distributors", Administrative Science Quarterly, Vol. 45, pp. 456-493.

Pratt, M.G., Rockmann, K.W. and Kaufmann, J.B. (2006), “Constructing Professional Identity : The Role of Work and Identity Learning Cycles in the Customization of Identity among Medical Residents", Academy of Management Journal, Vol. 49 No. 2, pp. 235-262.

Ruef, M. (2010), “The entrepreneurial group: Social identities, relations, and collective action”.

Siles, I. (2012), "Web technologies of the self: The arising of the 'Blogger' identity", Journal of Computer-Mediated Communication, Vol. 17 No. 4, pp. 408-421.

Sparrow, P.R. (2000), "New employee behaviours, work designs and forms of work organization: what is in store for the future of work?", Journal of Managerial Psychology, Vol. 15 No. 3, pp. 202-218.

Spreitzer, G.M., Cameron, L. and Garrett, L. (2017), “Alternative Work Arrangements: Two Images of the New World of Work", Annual Review of Organizational Psychology and Organizational Behavior, Vol. 4, pp. 473-499.

Steelman, Z.R., Hammer, B. and Limayem, M. (2014), "Data Collection in the Digital Age: Innovative Alternatives to Student Samples”, MIS Quarterly, Vol. 38 No. 2, pp. 355-378.

Stein, M.-K., Galliers, R.D. and Markus, M.L. (2013), “Towards an understanding of identity and technology in the workplace", Journal of Information Technology, Vol. 28, pp. 167182.

Stone, D.L., Deadrick, D.L., Lukaszewski, K.M. and Johnson, R. (2015), "The influence of technology on the future of human resource management", Human Resource Management 
Forthcoming Journal of Managerial Psychology

PLEASE DO NOT DISTRIBUTE WITHOUT AUTHORS'PERMISSION

Review, Elsevier Inc., Vol. 25 No. 2, pp. 216-231.

Strauss, A. and Corbin, J. (1998), "Basics of qualitative research: Procedures and techniques for developing grounded theory".

Thatcher, S.M.B. and Zhu, X. (2006), "Changing identities in a changing workplace: Identification, identity enactment, self-verification, and telecommuting", Academy of Management Review, Vol. 31 No. 4, pp. 1076-1088.

Wiesenfeld, B.M., Raghuram, S. and Garud, R. (1999), "Communication patterns as determinants of organizational identification in a virtual organization", Organization Science, Vol. 10 No. 6, pp. 777-790.

Wiesenfeld, B.M., Raghuram, S. and Garud, R. (2001), "Organizational identification among virtual workers: The role of need for affiliation and perceived work-based social support", Journal of Management, Vol. 27 No. 2, pp. 213-229. 
Table 1. Information about informants.

General information about informants

\begin{tabular}{lc}
\hline $\begin{array}{l}\text { Total number of informants } \\
\text { (and number of interviews) }\end{array}$ & 46 \\
\hline $\begin{array}{l}\text { Average years of engagement in online } \\
\text { work }\end{array}$ & 2,5 years \\
\hline Average age & 27 years \\
\hline $\begin{array}{l}\text { Number of Top Performers (labeled as } \\
\text { Top performers by the platform) }\end{array}$ & 22 \\
\hline $\begin{array}{l}\text { Number of informants working } \\
\text { exclusively on the platform }\end{array}$ & 17 (5 are students $)$ \\
\hline $\begin{array}{l}\text { Informants performing offline activities } \\
\text { related to online activities }\end{array}$ & 7 (1 is a student $)$ \\
\hline $\begin{array}{l}\text { Informants performing offline activities } \\
\text { not related to online activities }\end{array}$ &
\end{tabular}

\section{Informants by location and online job}

\begin{tabular}{ll}
\hline 24 IT developers & 15 informants from Europe (Italy, Spain, Portugal, \\
& UK, France, Russia) \\
& 9 informants from Asia (India, Pakistan, \\
& Bangladesh) \\
\hline 6 Virtual assistants and translators & 3 informants from Europe (Norway, Romania) \\
& 3 informants from Asia (Pakistan, Indonesia) \\
\hline 16 Graphic designers & 9 informants from Europe (Italy, Spain, Ukraine) \\
& 7 informants from US \\
\hline
\end{tabular}




\section{Forthcoming Journal of Managerial Psychology PLEASE DO NOT DISTRIBUTE WITHOUT AUTHORS' PERMISSION}

Figure 1. Data structure

\section{First order (informant) concepts}

e.g. Informants expressing the need to gain extra-money

e.g. Informants describing the willingness to make something useful out of their spare time

e.g. Informants expressing the need to do exciting job-related activities e.g. Informants describing their previous or current traditional jobs as repetitive or boring

e.g. Informants expressing the need to balance family responsibilities and working activities

e.g. Informants willing to work remotely for location choices

e.g. Informants wanting to gain experiences to use in the offline market e.g. Informants wanting to stay updated on the latest developments in their job and keep on learning

e.g. Informants joining the platform for the lack of alternative job offers e.g. Informants having difficulties in finding jobs related to their skills in the traditional market

e.g. Informants complaining about competing with different prices e.g. Informants describing the need to continuously commit to the platform, to be «always online» for replying to clients and catch jobs

e.g. Informants feeling constrained in developing long-term relations e.g. Informants continuously reiterating the hiring process e.g. Informants expressing feelings of job insecurity

e.g. Informants lamenting superficial support from the platform e.g. Informants acknowledging the need to learn how to deal directly with clients

e.g. Informants surfing other freelancers' profiles

e.g. Informants adapting their services to those required on the platform

e.g. Informants learning about the skills sold on the platform

e.g. Informants using job applications to fit job calls

e.g. Informants building a portfolio on their profiles

e.g. Informants validating declared competences with official tests

e.g. Informants valuing the platform for giving access to many

opportunities and adjusting their strategies to obtain jobs

e.g. Informants having the possibility to fully express professional skills

e.g. Informants thinking about personal distinctive traits

e.g. Informants empowering their uniqueness in the market

e.g. Informants communicating to clients what makes them unique

e.g. Informants acknowledging the value of their skills as communicators and negotiators

e.g. Informants developing tools for managing their business

e.g. Informants thinking about themselves as being responsible and in charge for their own business

e.g. Informants setting their prices to be competitive

e.g. Informants designing the services to be offered on the platform

e.g. Informants thinking about the subset of clients they want to attract

e.g. Informants expressing the desire to build a private network of clients

e.g. Informants opening personal web sites online

e.g. Informants acknowledging benefits of working outside companies

e.g. Informants expressing the desire to found a start-up

e.g. Informants building and managing local teams

e.g. Informants creating agencies' profile on the platform
Second order themes

Aggregate analytical

dimensions

\begin{tabular}{|c|}
\hline $\begin{array}{c}\text { Monetary } \\
\text { Compensation }\end{array}$ \\
\hline Fun \\
\hline Work flexibility \\
\hline Learning \\
\hline $\begin{array}{l}\text { Stagnant Labor } \\
\text { Market }\end{array}$ \\
\hline Global Competition \\
\hline $\begin{array}{l}\text { Short-term } \\
\text { Contracts }\end{array}$ \\
\hline Lack of Support \\
\hline
\end{tabular}

Motives to join the Online Platform

Constraining

Online

Environment

\begin{tabular}{|c|}
\hline $\begin{array}{c}\text { Acquiring Knowledge } \\
\text { of the Market }\end{array}$ \\
\hline Trying to Sell Skills \\
\hline
\end{tabular}

\begin{tabular}{|c|}
\hline $\begin{array}{c}\text { Experimenting with } \\
\text { Different }\end{array}$ \\
\hline
\end{tabular}

Different

Opportunities

Becoming a Unique
Online Worker

Becoming your own
sponsor

Becoming your own boss

Aggressively

competing to position oneself on the market

Strengthening the

Importance of Independence

Proactively Creating one's own Business
Strategic Use of

Technological Features

Work Identity

Construction

Development of an

Entrepreneurial

Orientation 
Forthcoming Journal of Managerial Psychology

\section{PLEASE DO NOT DISTRIBUTE WITHOUT AUTHORS' PERMISSION}

Figure 2. Grounded model.

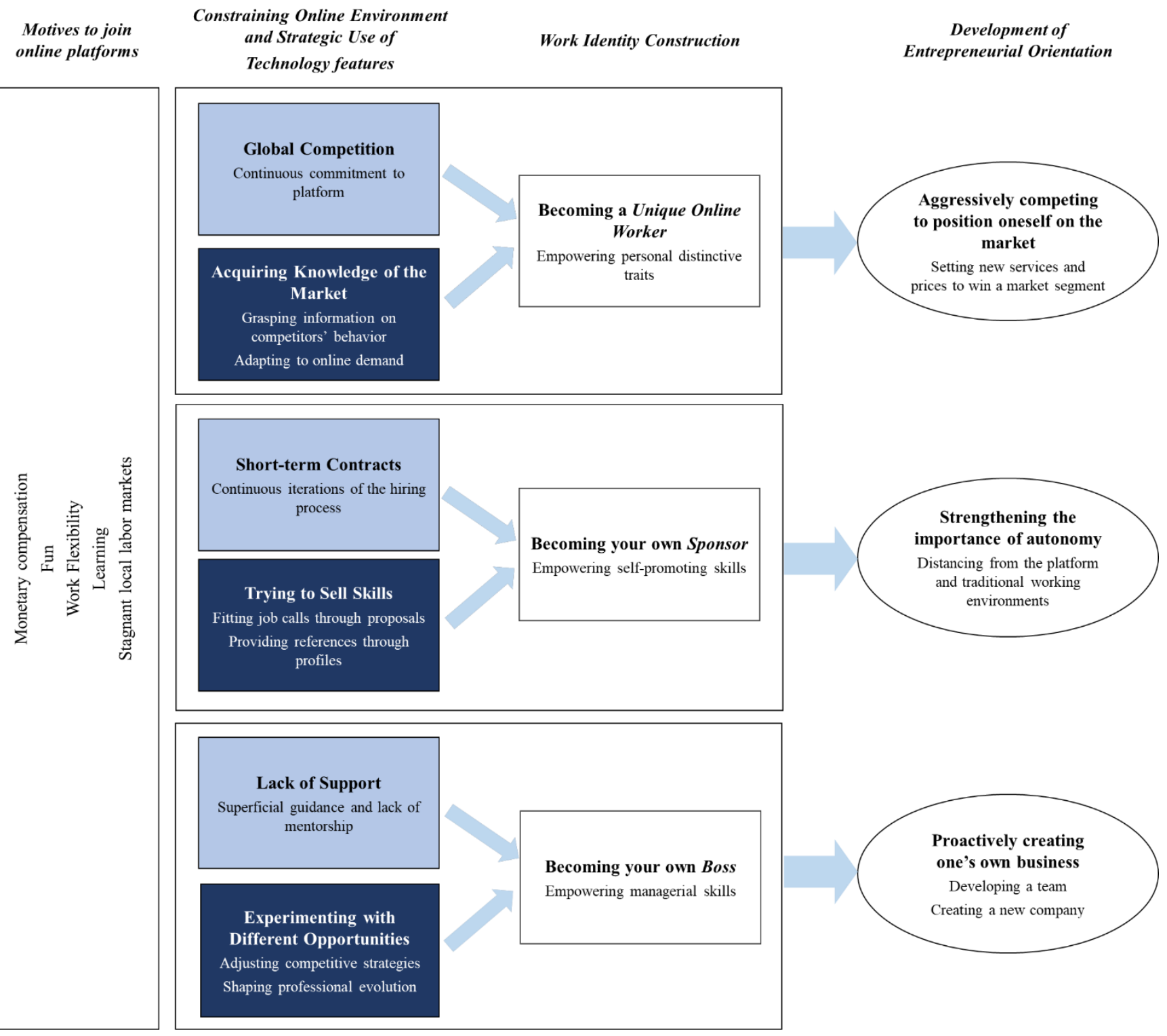

Constraining Online Environment

Strategic Use of Technology features 
Figure 3. Example of Kate's job applications at different stages of her experience on the platform.

JOB APPLICATION 1 - Describing distinctive traits

Dear [client name],

Thank you for contacting me and inviting me to do the illustrations for [resume of job description].

I'm a graduate student from [country] and studied at [university]. During my studies I've learned from [description of experience]. I love experimenting with a variety of art styles and my work is always personalized to each specific project.

I have experience working as an illustrator for [previous experience] (right now I'm working on [current job]). I not only can draw your stories in the requested style, but I can also see them through to final layout for both digital and printed form.

If chosen for the project, I can guarantee:

[service 1] [service 2] [service 3]

I love the [example] you've included in the description and I hope to be part of your project, bringing beautiful illustrations to match [job description].

I look forward to hearing from you!

Best regards,

Kate

JOB APPLICATION 2 - Sponsoring work through a personal web site

Hello [client name],

I read your job posting yesterday and was immediately intrigued. When [name of platform] invited me to interview, I knew I had to reach out to you!

I'm a graduate student from [country] and studied at [university]. During my studies I've learned from [description of experience]. I love experimenting with a variety of art styles and my artwork is always personalized to each specific project.

My art varies from traditional to digital and from [another example]. I have extensive knowledge on the know-hows to creating a graphic [job description], covering all aspects, including: XXXX.

With any given project, I always guarantee:

[service 1] [service 2]

More samples of my artwork can be found at: [personal web site]

Please feel free to reach out to me with any questions. I look forward to hearing from you!

Best regards,

Kate 
JOB APPLICATION 3 - Presenting herself as the head of a team

Dear [client name],

Thank you for the invitation to apply to your job!

I head a team of creative professionals that specialize in [specialization description]. We can take a project from initial conception and design through [service description].

Production steps:

[step 1]

[step 2]

[step 3]

[step 4]

We additionally offer [other services].

As I am also an Illustrator on our team, we take great pride in providing beautiful artwork that is always personalized to each specific project.

I will be available as the point of communication for all project related questions and needs. I have added you to [communication technology] and can be reached at [nickname].

I look forward to hearing more details about [job description]!

Best regards,

Kate 